\title{
On Banach Fixed Point Theorem Solving a Special Kind of Fractional Differential Equation
}

\author{
Maha Abd Al-Wahab \\ Department of Applied Science University of Technology Baghdad-Iraq
}

\begin{abstract}
In this paper we study the existence of a unique continuous function $y=y(x)$ on $I=(a, a+h]$ solution for the fractional differential equation $y^{(\alpha)}(x)=\lambda f(y(x))$ and $y^{(\alpha-1)}(a)=\mu$, $\mu$ is some constant, $0<\alpha \leq 1$, using Banach fixed point theorem.

keywords: Fractional differential equation, Banach fixed point theorem.
\end{abstract}

\section{Introduction}

Differential equations of fractional orderoccur more frequently in different research such as physics, control of dynamical systems, engineering, chemistry etc. Recently, many researchers paid attention to existence results of solution of fractional differential equations (see([1]...[5]). In this study we used Banach fixed point theorem to prove that there is a continuous function $y(x)$ on $\mathrm{I}=(\mathrm{a}, \mathrm{a}+\mathrm{h}]$ solution for the fractional differential equation $y^{(\alpha)}(x)=\lambda f(y(x))$ and $y^{(\alpha-1)}(a)=\mu, \mu$ is some constant, $0<\alpha \leq 1$.

\section{Preliminaries}

In this section we introduce notations, definitions and preliminary facts which are used throughout this paper.

Definition (2-1)([6]): Let $\mathrm{M}_{1}=\{\mathrm{g}: \mathrm{g}$ is a real valued function and continuous on the interval [a,b] $\}$. Let the norm $\|\cdot\|_{0}$ on $\mathrm{M}_{1}$ be defined as:

$$
\|g\|_{o}=\sup _{\lambda \in[a, b]}\{|\operatorname{g}(\mathrm{x})|\}
$$

Lemma (2-1)([6]):The space $\left(\mathrm{M}_{1},\|\cdot\|_{0}\right)$ is a Banach space, where $\mathrm{M}_{1}$ is defined in definition (2-1).

Lemma (2-2)([7]): Let $0<\alpha \leq 1$ and $f, g$ be continuous functions on $(a, \infty)$, where $a \in R$ and such that $\sup \{|\mathrm{f}(\mathrm{g}(\mathrm{x}))|: \mathrm{x} \in(\mathrm{a}, \infty)\}=\mathrm{M}<\infty$. Define $\mathrm{f}_{\alpha}(\mathrm{x})=\frac{\mu(\mathrm{x}-\mathrm{a})^{\alpha-1}}{\Gamma(\alpha)}+\frac{1}{\Gamma(\alpha)} \int_{a}^{x}(x-t)^{\alpha-1} \cdot f(g(x)) d t$, for all $\mathrm{x}>\mathrm{a}, \mu$ is some constant. Then $\mathrm{f}_{\alpha} \in \mathrm{c}(\mathrm{a}, \infty)$.

Lemma (2-3)([7]): Let us define $\mathrm{F}_{\alpha}(\mathrm{x})=(\mathrm{x}-\mathrm{a})^{1-\alpha} \mathrm{f}_{\alpha}(\mathrm{x})$ on $(\mathrm{a}, \infty)$, where $\mathrm{f}_{\alpha}$ define in lemma $(2-2)$ and $0<\alpha \leq 1$.Then $\mathrm{F}_{\alpha} \in \mathrm{c}[\mathrm{a}, \infty]$.

Definition (2-2)([8]):Let $\mathrm{p}, \mathrm{q}>0$ the $\int_{0}^{1} x^{p-1}(1-x)^{q-1} d x$ exists and is define for the Beta function as follows

$$
\beta(p, q)=\int_{0}^{1} x^{p-1}(1-x)^{q-1} d x
$$

Definition (2-3)([9]): Let $\left(\mathrm{G},\|\cdot\|_{0}\right)$ is a normed space, then a mapping $\mathrm{T}: \mathrm{G} \rightarrow \mathrm{G}$ is said to be a constraction on $\mathrm{G}$ if there exists a constant $\mathrm{k}$ with $0 \leq \mathrm{k}<1$ such that $\|\mathrm{T}(\mathrm{x})-\mathrm{T}(\mathrm{y})\| \leq \mathrm{k}\|x-y\|$ for all $\mathrm{x}, \mathrm{y} \in \mathrm{G}$.

Lemma (2-4)([10]): [Banach fixed point]

If $\left(\mathrm{G},\|\cdot\|_{0}\right)$ is a complete normed space $\mathrm{T}: \mathrm{G} \rightarrow \mathrm{G}$ is a constraction on mapping, then $\mathrm{T}$ has one and only one fixed point in G.

Definition (2-4)([11]): Let $f$ be Lebesque- measurable function defined a.e on [a, $b]$, if $\alpha>0$ then we define

$$
{ }_{a}^{b}{ }^{\alpha} f=\frac{1}{\Gamma(\alpha)} \int_{a}^{b} f(t)(b-t)^{\alpha-1} d t
$$

provided the integral (Lebesque) exists.

Lemma (2-5)([6]):Let $\alpha, \gamma \in \mathrm{R}, \gamma>-1$. If $\mathrm{x}>\mathrm{a}$ then 


$$
\mathrm{I}_{a}^{\alpha} \frac{(t-a)^{\gamma}}{\Gamma(\gamma+1)}=\left\{\begin{array}{cc}
\frac{(\alpha-a)^{\alpha+\gamma}}{\Gamma(\alpha+\gamma+1)}, & \alpha+\gamma \neq \text { negative integers } \\
0 \quad, & \alpha+\gamma=\text { negative integers }
\end{array}\right.
$$

Lemma (2-6) ([7]):If $0<\alpha \leq 1$ and $f(x)$ is continuous on (a,b], $|f(x)| \leq M$ for all $x \in(a, b]$ (where $M \in R^{+}, M>0$ ). Then

$$
\stackrel{\mathrm{I}}{x}_{a}^{-\alpha} \stackrel{\mathrm{I}}{\mathrm{I}}_{a}^{\alpha} \mathrm{f}=\mathrm{f}(x) \quad \text { for all } \mathrm{x} \in(\mathrm{a}, \mathrm{b}]
$$

Definition (2-5) ([11]): If $\alpha \in \mathrm{R}, \mathrm{f}$ is defined a.e on the interval [a, b], we define

$$
\frac{d^{\alpha} f}{d x^{\alpha}}=f^{\alpha}(x)=\stackrel{\mathrm{I}}{a}^{-\alpha} f \quad \text { for all } \mathrm{x} \in(\mathrm{a}, \mathrm{b}]
$$

provided that $\stackrel{\mathrm{I}}{\mathrm{I}}^{-\alpha} f$ exists.

Theorem (2-1)([11]): Let $0<\alpha \leq 1$ and $\gamma$ be positive constant. Let $g(x)=\left(g_{1}(x), g_{2}(x), \ldots, g_{n}(x)\right)^{T}, x \in[a, \infty)$, where $\mathrm{g}_{\mathrm{i}}$ are continuous on $[\mathrm{a}, \infty), \mathrm{i}=1,2, \ldots, \mathrm{n}$ and $|\mathrm{g}(\mathrm{x})|=\left(\sum_{i=1}^{n} \mathrm{~g}_{\mathrm{i}}^{2}\right)^{\frac{1}{2}}$ and $|\mathrm{g}(\mathrm{x})| \leq \mathrm{x}+\mathrm{c}$, where $\mathrm{c}$ is positive constant. Let $\mathrm{f}_{\mathrm{i}}=\left(\mathrm{f}_{1}, \mathrm{f}_{2}, \ldots, \mathrm{f}_{\mathrm{n}}\right)^{\mathrm{T}}$ such that $\mathrm{f}_{\mathrm{i}} \in[\mathrm{a}, \infty)$ and $\sup \{|\mathrm{f}(\mathrm{x})|: \mathrm{x} \in[\mathrm{a}, \infty)\}=\mathrm{M}<\infty$. Choose $\lambda$ such that $\lambda<\left(e^{\alpha}\left(\frac{c}{\alpha}\right)^{\alpha}\right)^{-1}$. Then there exists continuous vector function $\mathrm{y}(\mathrm{x})=\left(\mathrm{y}_{1}(\mathrm{x}), \mathrm{y}_{2}(\mathrm{x}), \ldots, \mathrm{y}_{\mathrm{n}}(\mathrm{x})\right)^{\mathrm{T}}, \mathrm{x} \in(\mathrm{a}, \infty)$ such that $\mathrm{y}^{(\alpha)}(\mathrm{x})=\lambda \mathrm{f}(\mathrm{y}(\mathrm{x}))$, $\mathrm{x} \in(\mathrm{a}, \infty) \quad$ with $\mathrm{y}^{(\alpha-1)}(\mathrm{a})=\mu$, where $\mu=\left(\mu_{1}, \quad \mu_{2}, \ldots, \mu_{\mathrm{n}}\right)^{\mathrm{T}}$ is some constant vector and satisfied $|\mathrm{y}(\mathrm{x})|<\exp \left(\alpha \mathrm{c}^{-1}|\mathrm{x}|\right) \cdot$ constant.

\section{Main Results}

In this section we prove the existence of a unique continuous function $y(x)$ on $I=(a, a+h]$ solution for the fractional differential equation $y^{(\alpha)}(x)=\lambda f(y(x))$, and $y^{(\alpha-1)}(a)=\mu$, where $\mu$ is some constant, , $0<\alpha \leq 1$, using Banach fixed point theorem.

Theorem (3):Let $0<\alpha \leq 1, M, A>0$ and $a \in R$ and $I=(a, a+h]$, let further the constant $b, h, \lambda>0$ and $K, L, \lambda$ satisfy the relations

$L=\frac{\lambda A h^{\alpha} \beta(\alpha, \alpha)}{\Gamma(\alpha)}<1$ and $\operatorname{Mh} \lambda<\mathrm{K} \Gamma(\alpha+1)$.

Let $\mathrm{D}$ be a region in the $\mathrm{x}, \mathrm{y}$ plane which contains the set

$\mathrm{C}=\left\{(\mathrm{x}, \quad \mathrm{y}): \quad \mathrm{x} \in \mathrm{I}, \quad\left|(\mathrm{x}-\mathrm{a})^{1-\alpha} \mathrm{y}-\mathrm{b}\right| \leq \mathrm{k}\right\}, \quad$ let $\mathrm{f}(\mathrm{x}, \quad \mathrm{y}) \quad$ be $\mathrm{a}$ continuous function on $\mathrm{D}$ such that $|\mathrm{f}(\mathrm{x}, \quad \mathrm{y})| \leq \mathrm{M}$ for all $(\mathrm{x}, \quad \mathrm{y}) \in \mathrm{D}$ and $\left|\mathrm{f}\left(\mathrm{x}, \mathrm{y}_{1}\right)-\mathrm{f}\left(\mathrm{x}, \mathrm{y}_{2}\right)\right| \leq \mathrm{A}\left|\mathrm{y}_{1}-\mathrm{y}_{2}\right|$ for all $\left(\mathrm{x}, \mathrm{y}_{1}\right),\left(\mathrm{x}, \mathrm{y}_{2}\right) \in \mathrm{D}$. Then there exists a unique continuous function $\mathrm{y}=\mathrm{y}(\mathrm{x})$ on $\mathrm{I}$ which is solution for the

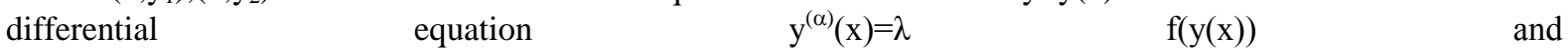
$\mathrm{y}^{(\alpha-1)}(\mathrm{a})=\mu$, where $\mu$ is some constant.

Proof: let $\mathrm{b}=\frac{\mu}{\Gamma(\alpha)}$ then $\mathrm{b} \in \mathrm{c}[\mathrm{a}, \mathrm{a}+\mathrm{h}]$.

Let $\left(\mathrm{M}_{1}, \quad\|\cdot\|_{0}\right)$ be the normed space which has been defined in definition (2-1), from lemma (2-1) $\left(\mathrm{M}_{1},\|\cdot\|_{\mathrm{o}}\right)$ is a complete normed space. Define $\mathrm{H}=\left\{\mathrm{G}: \mathrm{G} \in \mathrm{M}_{1},\|\mathrm{G}-\mathrm{b}\|_{\mathrm{o}} \leq \mathrm{k}\right\}$, we shall show that $\mathrm{H}$ is a closed subset of $\mathrm{M}_{1}$. For if $\left\{G_{n}\right\}_{n=1}^{\infty}$ is a sequence in $\mathrm{H}$ such that $\lim _{n \rightarrow \infty} G_{n}=G, G \in M_{1}$. Then given $\varepsilon>0$ there exist $\mathrm{N} \in \mathrm{Z}^{+}$such that for all $\mathrm{n} \geq \mathrm{N}$ we have $\left\|\mathrm{G}_{\mathrm{n}}-\mathrm{G}\right\|_{0}<\varepsilon$. Since $\|\mathrm{G}-\mathrm{b}\|_{\mathrm{o}} \leq\left\|\mathrm{G}-\mathrm{G}_{\mathrm{n}}\right\|_{\mathrm{o}}+\left\|\mathrm{G}_{\mathrm{n}}-\mathrm{b}\right\|_{\mathrm{o}}<\varepsilon \mathrm{k}$ and $\varepsilon$ is arbitrary, it follows that $\|\mathrm{G}-\mathrm{b}\|_{\mathrm{o}} \leq \mathrm{k}$ and this shows that $\mathrm{G} \in \mathrm{H}$ and consequently $\mathrm{H}$ is closed. Since every closed subset of a complete space is complete, hence $\mathrm{H}$ is complete. Now consider the following equation:

$$
\mathrm{y}(\mathrm{x})=\frac{\mu(\mathrm{x}-\mathrm{a})^{\alpha-1}}{\Gamma(\alpha)}+\frac{1}{\Gamma(\alpha)} \int_{a}^{x}(x-t)^{\alpha-1} f(y(t)) d t, \text { for all } \mathrm{x} \in(\mathrm{a}, \mathrm{a}+\mathrm{h}] .
$$


Then from lemma (2-2) we have $\mathrm{y} \in \mathrm{c}(\mathrm{a}, \mathrm{a}+\mathrm{h}]$, and so

$(\mathrm{x}-\mathrm{a})^{1-\alpha} \mathrm{y}(\mathrm{x})=b+\frac{(\mathrm{x}-\mathrm{a})^{1-\alpha}}{\Gamma(\alpha)} \int_{a}^{x}(x-t)^{\alpha-1} f(y(t)) d t$ for all $\mathrm{x} \in(\mathrm{a}, \mathrm{a}+\mathrm{h}]$

Define

$$
\mathrm{G}(\mathrm{x})=(\mathrm{x}-\mathrm{a})^{1-\alpha} \mathrm{y}(\mathrm{x})
$$

for

all

$\mathrm{x} \in(\mathrm{a}, \mathrm{a}+\mathrm{h}], \mathrm{F}(\mathrm{x}$,

$y(x))=(x-a)^{1-\alpha} f(y(t))$,

$\mathrm{a} \leq \mathrm{t}<\mathrm{x} \leq \mathrm{a}+\mathrm{h} \ldots(3.2)$

Then (3.1) takes the form $\mathrm{G}(\mathrm{x})=b+\frac{1}{\Gamma(\alpha)} \int_{a}^{x}(x-t)^{\alpha-1} F(x, y(t)) d t$ for all $\mathrm{x} \in[\mathrm{a}, \mathrm{a}+\mathrm{h}]$,

Since $|F(x, y(t))|=\left|(x-a)^{1-\alpha} f(y(t))\right| \leq h^{1-\alpha} M$

Therefore by lemma (2-3), the integral $\int_{a}^{x}(x-t)^{\alpha-1} F(x, y(t)) d t \quad$ exists for all $\mathrm{x} \in[\mathrm{a}, \mathrm{a}+\mathrm{h}]$, thus $\mathrm{G} \in \mathrm{c}[\mathrm{a}, \mathrm{a}+\mathrm{h}]$ and hence $\mathrm{G} \in \mathrm{M}_{1}$.

Furthermore $\|G-b\|_{o}=\sup _{x \in[a, a+h]}\{|\mathrm{G}(\mathrm{x})-\mathrm{b}|\}=$

$$
\sup _{x \in[a, a+h]}\left\{\left|(x-a)^{1-\alpha} \mathrm{y}(\mathrm{x})-\mathrm{b}\right|\right\} \leq k \text { hence } \mathrm{G} \in \mathrm{H} \text {. }
$$

Now define an operator $\mathrm{T}$ on $\mathrm{H}$ as follows.For $\mathrm{G} \in \mathrm{H}$

$\mathrm{TG}(\mathrm{x})=b+\frac{\lambda}{\Gamma(\alpha)} \int_{a}^{x}(x-t)^{\alpha-1} F(x, y(t)) d t$ for all $\mathrm{x} \in[\mathrm{a}, \mathrm{a}+\mathrm{h}]$,Since by lemma (2-3) the integral $\int_{a}^{x}(x-t)^{\alpha-1} F(x, y(t)) d t$ exists for all $\mathrm{x} \in[\mathrm{a}, \mathrm{a}+\mathrm{h}]$ and $\mathrm{b} \in \mathrm{c}[\mathrm{a}, \mathrm{a}+\mathrm{h}]$, the $\mathrm{TG}(\mathrm{x})$ is well defined for all $\mathrm{x} \in[\mathrm{a}$, $\mathrm{a}+\mathrm{h}]$.

Next we shall show that $\mathrm{T}: \mathrm{H} \rightarrow \mathrm{H}$ and $\mathrm{T}$ is constraction mapping.

Indeed if $\mathrm{G} \in \mathrm{H}$ then we have

$$
\|T G-b\|_{o}=\sup _{x \in[a, a+h]}\{|\mathrm{TG}(\mathrm{x})-\mathrm{b}|\}
$$

$$
\leq \sup _{x \in[a, a+h]}\left\{\frac{\lambda}{\Gamma(\alpha)} \int_{a}^{x}(x-t)^{\alpha-1}|F(x, y(t))| d t\right\}
$$

Then from (3-3) we have

$$
\begin{aligned}
& \|T G-b\|_{o} \leq \sup _{x \in[a, a+h]}\left\{\frac{M h^{(1-\alpha)} \lambda}{\Gamma(\alpha)} \int_{a}^{x}(x-t)^{\alpha-1} d t\right\} \\
= & \sup _{x \in[a, a+h]}\left\{\frac{M h^{(1-\alpha)} \lambda}{\Gamma(\alpha)} \frac{(x-a)^{\alpha}}{\alpha}\right\} \\
\leq & \frac{M h \lambda}{\Gamma(\alpha+1)} \leq k .
\end{aligned}
$$

Thus $\mathrm{T} \in \mathrm{H}$ and hence $\mathrm{T}: \mathrm{H} \rightarrow \mathrm{H}$.

Let further $\mathrm{G}_{1}, \mathrm{G}_{2} \in \mathrm{H}$ then from (3.1) we have $\left\|T G_{1}-T G_{2}\right\|_{o}=\sup _{x \in[a, a+h]}\left\{\left|\mathrm{T} G_{1}(\mathrm{x})-\mathrm{T} G_{2}(\mathrm{x})\right|\right\}$

$$
\begin{aligned}
& =\sup _{x \in[a, a+h]}\left\{\mid \frac{\lambda}{\Gamma(\alpha)} \int_{a}^{x}(x-t)^{\alpha-1} F\left(x, y_{1}(t) d t-\frac{\lambda}{\Gamma(\alpha)} \int_{a}^{x}(x-t)^{\alpha-1} F\left(x, y_{2}(t) d t \mid\right\}\right.\right. \\
& \leq \sup _{x \in[a, a+h]}\left\{\frac{\lambda}{\Gamma(\alpha)} \int_{a}^{x}(x-t)^{\alpha-1} \mid F\left(x, y_{1}(t) d t-F\left(x, y_{2}(t) \mid d t\right\}\right.\right. \\
= & \sup _{x \in[a, a+h]}\left\{\frac{\lambda(x-a)^{1-\alpha}}{\Gamma(\alpha)} \int_{a}^{x}(x-t)^{\alpha-1}\left|f\left(y_{1}(t)\right)-f\left(y_{2}(t)\right)\right| d t\right\}
\end{aligned}
$$




$$
\begin{gathered}
\leq A \sup _{x \in[a, a+h]}\left\{\frac{\lambda(x-a)^{1-\alpha}}{\Gamma(\alpha)} \int_{a}^{x}(x-t)^{\alpha-1}\left|y_{1}(t)-y_{2}(t)\right| d t\right\} \\
=\operatorname{Asup}_{x \in[a, a+h]}\left\{\frac{\lambda(x-a)^{1-\alpha}}{\Gamma(\alpha)} \int_{a}^{x}(x-t)^{\alpha-1}(t-a)^{\alpha-1}\left|G_{1}(t)-G_{2}(t)\right| d t\right\} \\
\leq \operatorname{Asup}_{x \in[a, a+h]}\left\{\frac{\lambda(x-a)^{1-\alpha}}{\Gamma(\alpha)} \int_{a}^{x}(x-t)^{\alpha-1}(t-a)^{\alpha-1}\left\|G_{1}-G_{2}\right\|_{o} d t\right\} \\
=A \sup _{x \in[a, a+h]}\left\{\frac{\lambda\left\|G_{1}-G_{2}\right\|_{o}(x-a)^{1-\alpha}}{\Gamma(\alpha)} \int_{a}^{x}(x-t)^{\alpha-1}(t-a)^{\alpha-1} d t\right\} \ldots \text { (3.4) }
\end{gathered}
$$

Let $U=\frac{t-a}{x-a}$ then

and its follows from definition (2-2)

$$
\int_{a}^{x}(x-t)^{\alpha-1}(t-a)^{\alpha-1} d t=\int_{0}^{1} U^{\alpha-1}(1-u)^{\alpha-1}(x-a)^{2 \alpha-1} d u,
$$

$$
\int_{a}^{x}(x-t)^{\alpha-1}(t-a)^{\alpha-1} d t=(x-a)^{2 \alpha-1} \beta(\alpha, \alpha) \ldots
$$

From (3.4) and (3.5) we obtain

$$
\begin{gathered}
\left\|T G_{1}-T G_{2}\right\|_{o}=A \sup _{x \in[a, a+h]}\left\{\frac{\lambda(x-a)^{\alpha-1}\left\|G_{1}-G_{2}\right\|_{o}(x-a)^{2 \alpha-1} \beta(\alpha, \alpha)}{\Gamma(\alpha)}\right\} \\
=A \sup _{x \in[a, a+h]}\left\{\frac{\lambda(x-a)^{\alpha}\left\|G_{1}-G_{2}\right\|_{o} \beta(\alpha, \alpha)}{\Gamma(\alpha)}\right\} \\
\leq \frac{A \lambda h^{\alpha} \beta(\alpha, \alpha)\left\|G_{1}-G_{2}\right\|_{o}}{\Gamma(\alpha)} \\
=L\left\|G_{1}-G_{2}\right\|_{o}, 0<L<1
\end{gathered}
$$

It follows from definition (2-3) that in view of (3.6), it follows that $\mathrm{T}$ is a constraction on $\mathrm{H}$.

Hence by the Banach fixed point ((lemma (2-4)) there is one and only one $\mathrm{G} \in \mathrm{H}$ such that $\mathrm{T}(\mathrm{G}(\mathrm{x}))=\mathrm{G}(\mathrm{x})$, for all $x \in[a, a+h]$.

$$
\text { Thus } \mathrm{G}(\mathrm{x})=b+\frac{\lambda}{\Gamma(\alpha)} \int_{a}^{x}(x-t)^{\alpha-1} F(x, y(t)) d t \text { for all } \mathrm{x} \in[\mathrm{a}, \mathrm{a}+\mathrm{h}] \text {, }
$$

It follows from (3.2) that

$$
(\mathrm{x}-\mathrm{a})^{1-\alpha} \mathrm{y}(\mathrm{x})=\frac{\mu}{\Gamma(\alpha)}+\frac{\lambda}{\Gamma(\alpha)} \int_{a}^{x}(x-t)^{\alpha-1}(x-a)^{1-\alpha} f(y(t)) d t,
$$

and thus

$$
\mathrm{y}(\mathrm{x})=\frac{\mu(\mathrm{x}-\mathrm{a})^{\alpha-1}}{\Gamma(\alpha)}+\frac{\lambda}{\Gamma(\alpha)} \int_{a}^{x}(x-t)^{\alpha-1} f(y(t)) d t, \text { for all } \mathrm{x} \in(\mathrm{a}, \mathrm{a}+\mathrm{h}]
$$

Now by definition (2-4) we obtain

$$
\mathrm{y}(\mathrm{x})=\frac{\mu(\mathrm{x}-\mathrm{a})^{\alpha-1}}{\Gamma(\alpha)}+\lambda \mathrm{I}_{a}^{x} f \quad x \in(a, a+h]
$$

and so

$$
\mathrm{I}_{a}^{x} y=\mathrm{I}_{a}^{x} \frac{\mu(\mathrm{t}-\mathrm{a})^{\alpha-1}}{\Gamma(\alpha)}+\lambda \mathrm{I}_{a}^{x}{ }_{a}^{-\alpha} \mathrm{I}^{\alpha} f
$$

But from lemma (2-5) we have $\mathrm{I}_{a}^{x} \frac{(\mathrm{t}-\mathrm{a})^{\alpha-1}}{\Gamma(\alpha)}=0$ and by lemma(2-6) we get

$$
\mathrm{I}_{a}^{x}{ }^{-\alpha}{ }_{a}^{t}{ }^{\alpha} \mathrm{f}=\mathrm{f}(\mathrm{y}(\mathrm{x}))_{\text {for all } \mathrm{x} \in(\mathrm{a}, \mathrm{a}+\mathrm{h}]}
$$


Thus $\mathrm{I}_{a}^{x}-\alpha \mathrm{y}=\lambda \mathrm{f}(\mathrm{y}(\mathrm{x}))_{\mathrm{x} \in(\mathrm{a}, \mathrm{a}+\mathrm{h}]}$

Then by using definition (2-5) we get

$$
\mathrm{y}^{(\alpha)}(\mathrm{x})=\stackrel{\mathrm{I}}{\mathrm{I}}^{-\alpha} y=\lambda \mathrm{f}(\mathrm{y}(\mathrm{x}))_{\mathrm{x} \in(\mathrm{a}, \mathrm{a}+\mathrm{h}]}
$$

Furthermore from (3.7) we have

$$
\stackrel{\mathrm{I}}{x}^{1-\alpha} \mathrm{y}=\mathrm{I}_{a}^{x}{ }^{1-\alpha} \frac{\mu(\mathrm{t}-\mathrm{a})^{\alpha-1}}{\Gamma(\alpha)}+\lambda{\underset{a}{\mathrm{I}}}^{1-\alpha}{ }_{a}^{t}{ }^{\alpha} f
$$

It follows from lemma (2-5) that

$$
\begin{aligned}
& { }_{a}^{x}{ }^{1-\alpha} \mathrm{y}=\boldsymbol{\mu}+\lambda \mathrm{I}_{a}^{x}{ }^{1-\alpha}{ }_{a}^{t}{ }^{\alpha} f=\mu+\lambda \stackrel{\mathrm{I}}{x}^{1} f \\
& =\mu+\lambda \int_{a}^{x} f(y(t)) d t
\end{aligned}
$$

and so $\mathrm{I}_{a}^{x}{ }^{1-\alpha} \mathrm{y}$ exists for all $\mathrm{x} \in[\mathrm{a}, \mathrm{a}+\mathrm{h}]$

since by definition (2-5)

$$
y^{(\alpha-1)}(x)=\mathrm{I}_{a}^{x}{ }^{1-\alpha} \mathrm{y}
$$

therefore $y^{(\alpha-1)}(\mathrm{a})=\mu$

Now from theorem (2-1) equation (3.11) we have

then from theorem (2-1) equation (3.8) we have

$$
|F(x)| \leq b+|\lambda||k F(x)|
$$

$$
\begin{aligned}
& |F(x)| \leq b+|\lambda|\|F\|_{o} \frac{e^{\gamma c}}{\gamma^{\alpha}} e^{\gamma|x|} \\
& <b+\|F\|_{o} e^{\gamma|x|} \text { since } \gamma \mathrm{c}=\alpha \\
& =e^{\gamma|x|}\left(b e^{-\gamma|x|}+\|F\|_{o}\right) \\
& <e^{\gamma|x|}\left(b+\|F\|_{o}\right)
\end{aligned}
$$

thus by using theorem (2-1) equation (3.3) we obtain

$$
\begin{aligned}
& \left|(x-a)^{1-\alpha} y(x)\right|<e^{\gamma|x|}\left[b+\|F\|_{o}\right] \\
& h^{1-\alpha}|y(x)|<e^{\gamma|x|}\left[b+\|F\|_{o}\right] \\
& |y(x)|<e^{\gamma|x|} h^{\alpha-1}\left[b+\|F\|_{o}\right]
\end{aligned}
$$

and so the solution function satisfied

$$
|\mathrm{y}(\mathrm{x})|<\exp \left(\alpha \mathrm{c}^{-1}|\mathrm{x}|\right) \cdot \text { constant. }
$$

\section{References:}

[1] V. Lakshmikantham, S. Leela and J. Vasundhara; theory of fractional dynamic systems, Cambridge Academic publishes, Cambridge 2009.

[2] Sabatier, J.; Agrawal, O.P.; Tenveiro Machado, J. A; Advances in Fractional calculus; the oretical Developments and application in physics and Engineering, springer, 2007.

[3] O. K. Jaractat, A. A-omari, S. Momani, Existence of the mild solution for fractional semi linear initial value problem. Mon linear Analysis, 2008.

[4] A. A. Kilbas,H. M. Srirastara, J. J Trujillo, theory and applications of fractional differential equations, Elsevier, Amsterdam, 2006.

[5] M. Mater, on existence and uniqueness of the mild solution for fractional integro-differential equations, Journal of integral equations and applications, 2011.

[6] Al-Tabakchaly. M. A., on the existence and uniqueness for fractional differential equations, Msc. Thesis, University of Musol.

[7] Dr. Ahmed Zain-Abdin, Maha Abd Al-Wahab, Theorem on Certain Fractional Functions and Derivatives, Eng and Tech. Journal. Vol. 30, No. 2, 2012.

[8] Spanierkeith B. Oldham and Jerome, The Fractional Calculus, Theory and Application of Differentiation to Arbitrary Order Manufactured in the United state by Counter corporation: ISBN- 13:978-0-486-45001-8, 2006.

[9] A. F. Beardon, Constraction on the real line, Amer. Math. Monthly 113, 2006.

[10] Palais, R. A Simple proof of the Banach constraction principle, "J. fixed point theory appl." 2007.

[11] Maha Abd Al-Wahab, On the Existence and uniqueness for solution of system Fractional differential equations, IOSR Journal of Mathematics (IUSR-JM), 2012. 